\title{
Systemic and skin-targeting beneficial effects of lycopene-enriched ice cream: A pilot study
}

\author{
Marina P. Chernyshova, ${ }^{1}$ Dmitry V. Pristenskiy, ${ }^{1}$ Marina V. Lozbiakova, ${ }^{1}$ Natalia E. Chalyk, ${ }^{2}$ \\ Tatiana Y. Bandaletova, ${ }^{3}$ and Ivan M. Petyaev ${ }^{1 *}$ \\ ${ }^{1}$ Lycotec Ltd., Granta Park Campus, Cambridge, CB21 6GP, United Kingdom \\ ${ }^{2}$ Saratov State Medical University, Research Institute of Cardiology, 112 Bolshaya Kazachia Street, 410012, Saratov, Russian Federation \\ ${ }^{3}$ DiagNodus Ltd., Babraham Research Campus, CB22 3AT, Cambridge, United Kingdom
}

\begin{abstract}
The health-promoting dietary antioxidant lycopene has limited natural bioavailability, but lycopene-rich functional foods can improve its bioavailability. We assessed a new lycopene-enriched ice cream for systemic antioxidant effects and influence on morphological characteristics of facial skin surface in healthy volunteers. In a randomized crossover study, we used 4-wk dietary interventions with either control or lycopeneenriched ice cream. Samples of serum and residual skin surface components (RSSC) from facial skin were taken before interventions, at $2 \mathrm{wk}$, and at intervention end. Lycopene concentration, conventional blood biochemistry, and oxidative stress biomarkers comprising inflammatory oxidative damage and low-density lipoprotein peroxidase proteins were assessed in the serum. Lycopene-associated immunofluorescence, lipid droplet size, corneocyte desquamation, and microbial presence were measured in the RSSC. The results show that lycopene concentrations in the serum and skin steadily increased during lycopene-enriched ice cream consumption. Whereas we found no intervention-dependent changes in conventional biochemical parameters, both inflammatory oxidative damage and low-density lipoprotein peroxidase protein values significantly decreased by the end of intervention with lycopene-enriched ice cream, but remained unchanged during control ice cream consumption. Control ice cream significantly increased corneocyte desquamation and bacterial presence in the RSSC. These adverse effects, which could potentially predispose consumers to acne development, were absent when volunteers consumed lycopene-enriched ice cream. We concluded that lycopene-enriched ice cream is a new functional food with clear antioxidant properties. In addition, enrichment with lycopene may
\end{abstract}

Received June 26, 2018.

Accepted September 27, 2018.

*Corresponding author: petyaev@lycotec.com alleviate proinflammatory action of ice cream at the level of facial skin, thus decreasing diet-associated acne development risk in young consumers.

Key words: lycopene, ice cream, antioxidant effect, serum, skin surface

\section{INTRODUCTION}

As humans are not able to synthesize carotenoids, they depend entirely on consumption of fruits, vegetables, and nutritional supplements for dietary intake of carotenoids. Thus, regular consumption of fruits and vegetables rich in carotenoids exerts protective effects against the development of major chronic diseases, including type 2 diabetes, cardiovascular disease, and cancer (Kaulmann and Bohn, 2014). These beneficial effects are primarily attributed to antioxidant properties of carotenoids that reduce generation of reactive oxygen species that induce oxidative stress and are greatly implicated in disease causation and pathogenesis as well as aging process (Rao and Rao, 2007; Davies et al., 2017). In this sense, lycopene has been regarded as the most effective singlet oxygen quencher among all carotenoids due to its apolar and acyclic molecular structure (Tang et al., 2015).

Lycopene is a red, lipid-soluble carotenoid phytonutrient that is naturally produced in tomato and abundantly present in tomato-based products. It has been proven to possess high antioxidant and antitumor potentials that mitigate the damaging effects of oxidative stress (Thies et al., 2017). Consumption of lycopene-rich foods (especially tomatoes) or dietary supplements containing this carotenoid has been repeatedly demonstrated to produce health-promoting and antiaging effects (Moran et al., 2013; Petyaev, 2016; Costa-Rodrigues et al., 2018). Nevertheless, no clarity exists on the comparative efficiency of natural foods versus traditional pure supplements (Burton-Freeman and Sesso, 2014), and new versions of functional foods that can be defined as conventional foods enriched with 
health-promoting components (Rodgers, 2016; Hunter and Hegele, 2017) are actively being developed and investigated. Our previous studies have demonstrated the antihypertensive and oxidative stress-reducing effects of both lycopene combined with whey protein (Petyaev et al., 2012) and lycopene-containing dark chocolate (Petyaev et al., 2014).

Another intriguing aspect of this theme has emerged from our recent study, showing that the antioxidant action of another carotenoid, astaxanthin, not only produces beneficial systemic effects, but also appears to reverse skin aging (Chalyk et al., 2017b). Oxidative stress constitutes one of the key mechanisms responsible for both intrinsic and extrinsic (provoked by UV exposure and other external factors) skin aging (Kammeyer and Luiten, 2015), but in young people it can also lead to inflammatory changes, as it is a major component of acne pathogenesis (Al-Shobaili et al., 2013; Sahib et al., 2013). Human skin is a well-known target of lycopene, and its accumulation in this tissue during dietary supplementation is well proven (Blume-Peytavi et al., 2009; Meinke et al., 2010; Ross et al., 2011).

In the present study, we investigated blood lipids and oxidative stress markers as well as morphological changes of residual skin surface components (RSSC) from the facial skin surface in a group of healthy volunteers consuming lycopene-enriched ice cream. Fat-rich ice cream is a food well suited for combination with lipophilic lycopene, potentially providing both lowtemperature stabilization and increased bioavailability of carotenoids. However, ice cream consumption is also known to be associated with an increased risk of acne development (Ismail et al., 2012; Karadağ et al., 2017); therefore, it was interesting to find out whether lycopene antioxidant action may alleviate this risk. Our recently proposed method for noninvasive RSSC sampling (Chalyk et al., 2017a) provides a convenient tool for assessing early manifestations of oxidative stress on the surface of the facial skin. Therefore, we applied this new methodology in the study described in the current paper.

\section{MATERIALS AND METHODS}

\section{Ice Creams}

Raw Materials Used for Ice Cream Manufacturing. The following ingredients were employed for ice cream manufacturing (weight percentage of each ingredient is shown in parentheses): whole cow milk, $3.5 \%$ fat (41.8\%); cow butter, $82 \%$ fat (1.7\%); whipping cream, $33 \%$ fat $(36.4 \%)$; nonfat dried powdered milk $(5.1 \%)$; sugar powder $(14.2 \%)$; vanillin $(0.11 \%)$; gelatin $(0.6 \%)$; and lycopene $15 \%$ oleoresin $(0.09 \%)$. Lycopene was not added to the control ice cream. Lycopenecontaining and control vanilla ice cream mixes were formulated to contain above $40 \%$ TS (14\% milk fat, $14.2 \%$ sucrose, and $12 \% \mathrm{SNF}$ ) and have a freezing point of $-2.7^{\circ} \mathrm{C}$.

Ice Cream Preparation Process. A flowchart of ice cream preparation is shown in Figure 1. Unmodified lycopene 15\% oleoresin (Lycored SARL, Schaffhausen, Switzerland) was used for preparing lycopene-enriched ice cream. Lycopene-containing ice cream was prepared by initially blending $934 \mathrm{mg}$ of lycopene $15 \%$ oleoresin with $17 \mathrm{~g}$ of dairy butter at $40^{\circ}$ and then adding the resulting blend to the heated mix of liquid ingredients. The final lycopene concentration in the ice cream was $0.14 \mathrm{mg} / \mathrm{g}$. Eight identical batches of ice cream were prepared for the study (each consumed by volunteers within $1 \mathrm{wk}$, as described below). Microscopic characteristics of melted lycopene-enriched and control ice creams were assessed using Olympus BX41 laboratory microscope (Olympus, Tokyo, Japan) at 1,000× magnification. In addition, volunteers taking part in the study were asked to provide feedback on comparative sensory properties of the 2 ice creams.

\section{Subjects}

The present study was undertaken by Lycotec Ltd. (Cambridge, UK) in collaboration with the Institute of Cardiology of the Ministry of Health of the Russian Federation (Saratov, Russian Federation). The protocol of the study was duly approved by the local Ethics Committee in Saratov (FGBU SarNIIK 18.02.2014). All volunteers taking part in the study provided written informed consent. This study constitutes a part of an ongoing larger project that is registered as ISRCTN89815519 in the ISRCTN registry.

Ten healthy volunteers ( 5 men and 5 women, aged between 21 and $47 \mathrm{yr}$ ) that agreed to take part in the study were recruited in Saratov from the existing volunteer pool. All recruited volunteers were free of systemic chronic disorders, conditions affecting skin, and food allergies. None of them received lycopene-containing food supplements apart from those given during the study.

\section{Study Design and Dietary Intervention}

We used a randomized crossover study design with two 4-wk periods of dietary intervention and a washout period of 1 mo between them. During dietary intervention periods, study participants received daily ice cream portions of $50 \mathrm{~g}$ with the evening meal. For the lycopene-containing ice cream, the daily dose of lycopene was $7 \mathrm{mg}$. 


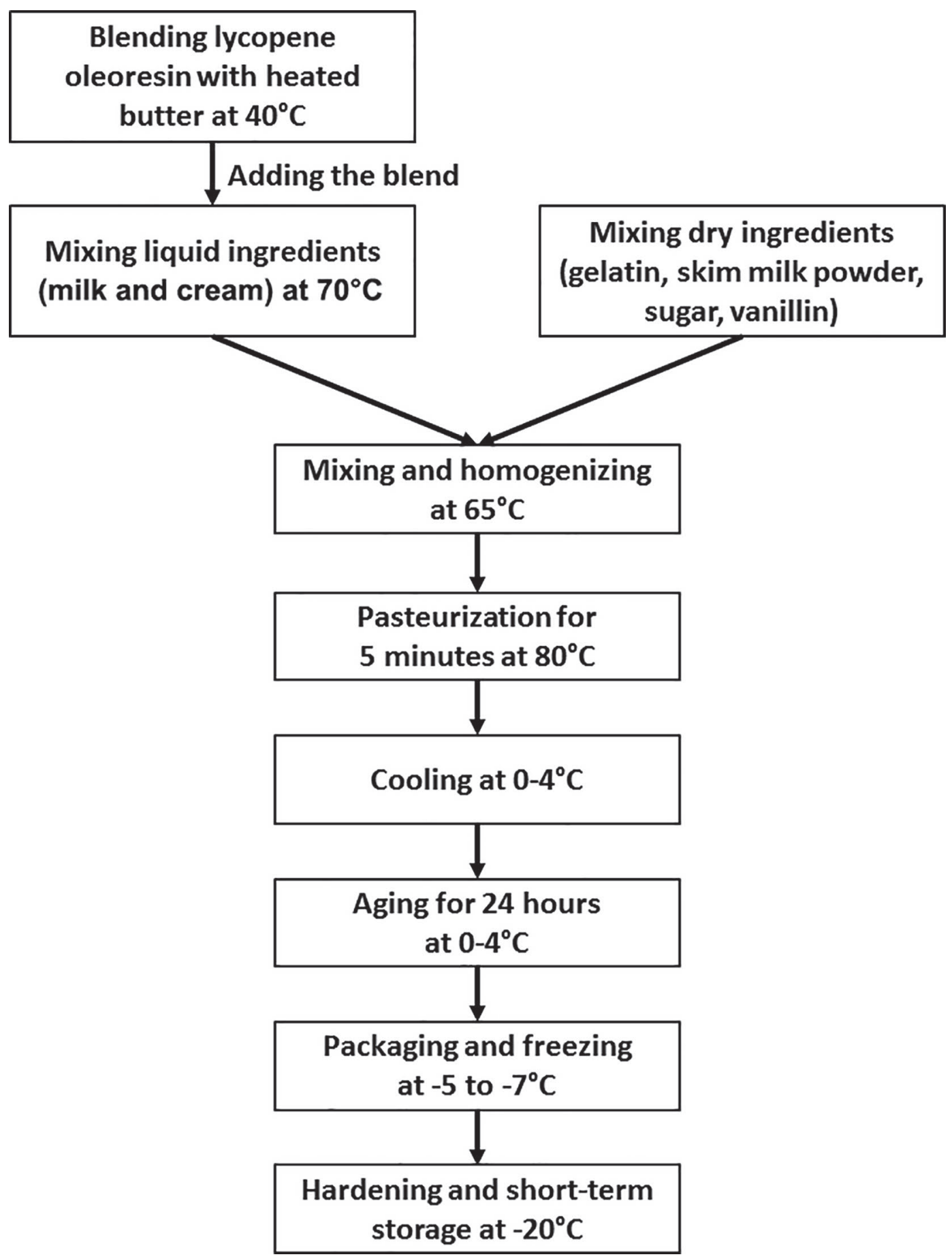

Figure 1. Flowchart outlining the preparation of lycopene-enriched ice cream.

At the beginning and end of each dietary intervention period, study participants had their body mass index determined by measuring body mass and height in the morning and then calculating the index in kilograms per meter ${ }^{2}$. Blood pressure measurements were also taken at these time points.

\section{Sample Collection and Preparation}

Blood samples were collected from all volunteers by phlebotomy in the morning after overnight fast. Blood sample collections were performed at the beginning of each dietary intervention period, after 2 wk of ice 
cream consumption, and at the end of each intervention period (4 wk). The serum was separated by centrifugation (15 min, 3,000 $\mathrm{rpm}, 4^{\circ} \mathrm{C}$ ), aliquoted, placed in code-labeled tubes for blinded analysis, and stored at $-80^{\circ} \mathrm{C}$ until use.

For collecting RSSC samples from the surface of the facial skin, all volunteers were requested to avoid facial hygienic manipulations for $24 \mathrm{~h}$ before sampling, which was carried out in the morning in parallel with blood sample collection, but only at the beginning and end of each dietary intervention. Sample collection and preparation was carried out as previously described (Chalyk et al., 2017a). Briefly, samples were taken using polyester swabs from the sides of the nose. During the procedure, 2 samples were taken ( 1 swab per side) and smears were prepared on 4 microscope slides. All prepared smears were thoroughly dried, coded to provide sample anonymity for blinded analysis, and stored at $-20^{\circ} \mathrm{C}$ until use.

\section{Lycopene Quantification in Serum Samples}

Lycopene concentration in serum samples was measured using HPLC (Diwadkar-Navsariwala et al., 2003) with modifications. Only samples from volunteers receiving lycopene-enriched ice cream were analyzed. Briefly, $400 \mu \mathrm{l}$ of serum was mixed with $400 \mu \mathrm{L}$ of ethanol and extracted twice with $2 \mathrm{~mL}$ of hexane. The combined hexane layers were evaporated to dryness under vacuum (Scan Speed 32 centrifuge, Labogene, Copenhagen, Denmark), and the residue was reconstituted to $100 \mu \mathrm{L}$ in sample solution (absolute ethanol: methylene chloride, 5:1 vol/vol). The specimens were centrifuged again $\left(15 \mathrm{~min}\right.$ at $10,000 \times g$ at $\left.4^{\circ} \mathrm{C}\right)$ and the supernatant was transferred to HPLC vials. The extract $(5 \mu \mathrm{L})$ was injected into an Acquity HSS T3 $75 \times 2.1 \mathrm{~mm}, 1.8-\mu \mathrm{m}$ column (Waters, Milford, MA) preceded by a Acquity HSS T3 $1.8-\mu \mathrm{m}$ VanGuard precolumn (Waters) and eluted isocratically at $45^{\circ} \mathrm{C}$ with the mobile phase (acetonitrile:0.08\% phosphoric acid solution:tert-Butyl methyl ether, 70:5:25 vol/vol/vol) at a flow rate of $0.5 \mathrm{~mL} / \mathrm{min}$. The peaks corresponding to lycopene isomers were detected by a Photodiode Array Detector (Waters) at $474 \mathrm{~nm}$. The peak areas were measured using Empower 3 software (Waters). Lycopene concentrations were calculated by reference to an analytical standard (lycopene from tomato, L9879, Sigma-Aldrich, St. Louis, MO).

\section{Lycopene Detection in RSSC Samples}

Immunofluorescent staining for lycopene was performed using dried RSSC smears collected from the surface of the facial skin. Desquamated corneocytes and sebum present in the samples were stained with fluorescein isothiocyanate-conjugated monoclonal antibodies against lycopene that were generated by our group (Tsibezov et al., 2017). Fluorescent staining intensity was assessed using Eclipse 50i microscope (Nikon, Tokyo, Japan) with a fluorescence attachment. Fluorescence levels in desquamated corneocytes and sebum background were evaluated semiquantitatively in 20 random microscope fields of view at $200 \times$ magnification. Fluorescence intensity in the samples was classified using the following scoring system: $0=$ no fluorescence; $0.5=$ traces of fluorescence; $1=$ weak fluorescence; 2 = moderate fluorescence; $3=$ strong fluorescence of occasional corneocytes or areas of sebum background; and $4=$ uniformly strong fluorescence of corneocytes or sebum. Fluorescence assessment in each smear with separate scores for corneocytes and sebum was repeated blindly 3 times.

\section{Determination of Biochemical Profiles and Oxidative Damage Biomarkers in Serum Samples}

Total cholesterol, triglycerides, high-density lipoproteins (HDL), low-density lipoproteins (LDL), glucose, C-reactive protein, total bilirubin, aspartate aminotransferase, and alanine aminotransferase were measured using commercially available analytical kits according to manufacturers' instructions (SigmaAldrich) at the beginning of dietary interventions, after 2 wk of ice cream consumption, and at the end of each intervention period (4 wk). In addition, oxidative damage biomarkers were measured. Inflammatory oxidative damage (IOD) was determined as previously described by our group (Petyaev et al., 2016). Activity of serum LDL peroxidase proteins ( LDL-Px) was measured as described elsewhere (Petyaev et al., 1998; Petyaev and Coussons, 1999).

\section{RSSC Morphology Analysis}

For morphological analysis of RSSC samples, one of the prepared slides was stained with hematoxylin and eosin to identify any cells or cell remnants. Lipid visualization and lipid droplet size evaluation on the second slide was performed using Oil Red O (Lipid Stain, ab150678, Abcam, Cambridge, UK). One more slide was stained with crystal violet solution (Gram staining) for assessing gram-positive microorganism presence level. The remaining slides were kept for future use.

All microscopy was performed using Olympus BX41 laboratory microscope (Olympus) at 1,000 $\times$ magnification by analyzing 40 fields of view within each smear. An Olympus DP71 camera was used for preparing photomicrographs. 
The RSSC analyses comprised lipid droplet size measurement, counting desquamated corneocytes, and bacterial presence evaluation. Details of these analytical procedures, including bacterial presence grading according to our bacterial presence assessment scale (BPAS), are described in our previous paper (Chalyk et al., 2017a). All samples were anonymized before microscopy to guarantee blind analysis.

\section{Data Analysis}

Results of all quantitative measurements (or microbial contamination degree counts) were analyzed using descriptive statistics (mean, SD, SE, median, and range values as well as 95\% CI were determined). A paired $t$-test (2-sided $P$-values calculated) was applied to determine statistical significance for the differences between time points during dietary interventions. Line charts were employed for presenting result changes during dietary intervention periods. All data handling and statistical analyses were performed using IBM SPSS 19.0 statistical package (IBM Inc., Armonk, NY).

\section{RESULTS}

\section{Characterization of Control and Lycopene- Enriched Ice Creams}

Feedback received from study participants indicated that lycopene-enriched ice cream had a distinct orange appearance. However, no difference in terms of sensory characteristics of the 2 ice creams was noted, and lycopene addition did not result in any change of ice cream flavor or texture. Subjects consumed ice creams only after short storage periods; therefore, long storage effects could not be assessed.

Microscopic analysis of melted ice cream samples (see Figure 2) has shown the expected presence of numerous fat globules, predominantly varying in size between 1 and $2 \mu \mathrm{m}$; however, much larger fat globule clusters were occasionally observed as well. In the lycopeneenriched ice cream, some fat globules were stained (orange-brownish color) stronger than others, and much denser particles, most probably lycopene crystals, were sometimes seen within confluent fat globule clusters (see Figure 2b).

\section{Lycopene Measurement in Serum and RSSC Samples During Consumption of Ice Cream}

Repeated measurements of serum lycopene concentration during lycopene-enriched ice cream consumption have demonstrated immediate rapid increase of lycopene concentration, which was significantly higher (paired $t$-test $P=0.006$ for comparison between intervention beginning and 2 -wk points) after $2 \mathrm{wk}$ of dietary intervention (see Figure 3A). Serum lycopene concentrations continued to grow after 2 wk, but more slowly, and we found no statistically significant difference $(P>0.05)$ between 2 -wk point and the end of dietary intervention.

Likewise, immunofluorescent detection of lycopene in RSSC samples has demonstrated steady increases in fluorescence intensity in both desquamated corneocytes and sebum (see Figures 3B and 3C). The increase of lycopene presence in corneocytes was faster in the second half of dietary intervention period. Whereas average levels of lycopene did not differ significantly between the beginning of the intervention and 2 -wk point, the difference in comparison to d 0 became highly significant at the end of intervention (paired $t$-test $P=0.006$ for comparison between intervention beginning and 4-wk points). In addition, we noted a significant increase of lycopene concentration in corneocytes during the last 2 wk of lycopene-enriched ice cream intake (paired $t$-test $P=0.037$ for comparison between 2 - and 4 -wk points). It is interesting that lycopene increase pattern in the unstructured sebum appeared to be different, as it was mostly confined to the first half of the intervention period (paired $t$-test $P=0.007$ for comparison between intervention beginning and 2 -wk points). Although a further increase was observed during the last $2 \mathrm{wk}$ of intervention, we observed no statistically significant difference of lycopene presence in the sebum between 2- and 4-wk points.

\section{General Characteristics of Study Participants and Serum Biochemistry Results}

Table 1 demonstrates the general characteristics of volunteers taking part in the study as well as results of routine biochemical tests. It shows that study participants were young people (average age $33.4 \mathrm{yr}$ ) with normal average BMI and normal blood pressure that remained stable throughout dietary intervention periods. Levels of the main classes of serum lipids (total cholesterol, triglycerides, LDL, and HDL) were certainly within the normal range, and dietary interventions did not result in any significant changes. Likewise, serum levels of glucose, C-reactive protein, and aspartate aminotransferase were normal and not affected by dietary interventions. Slight, but statistically significant increases $(P<0.05)$ of total bilirubin and alanine aminotransferase levels were observed at the end of dietary intervention periods for both control and lycopene-enriched ice cream (see Table 1); however, the values remained securely within the normal range. 

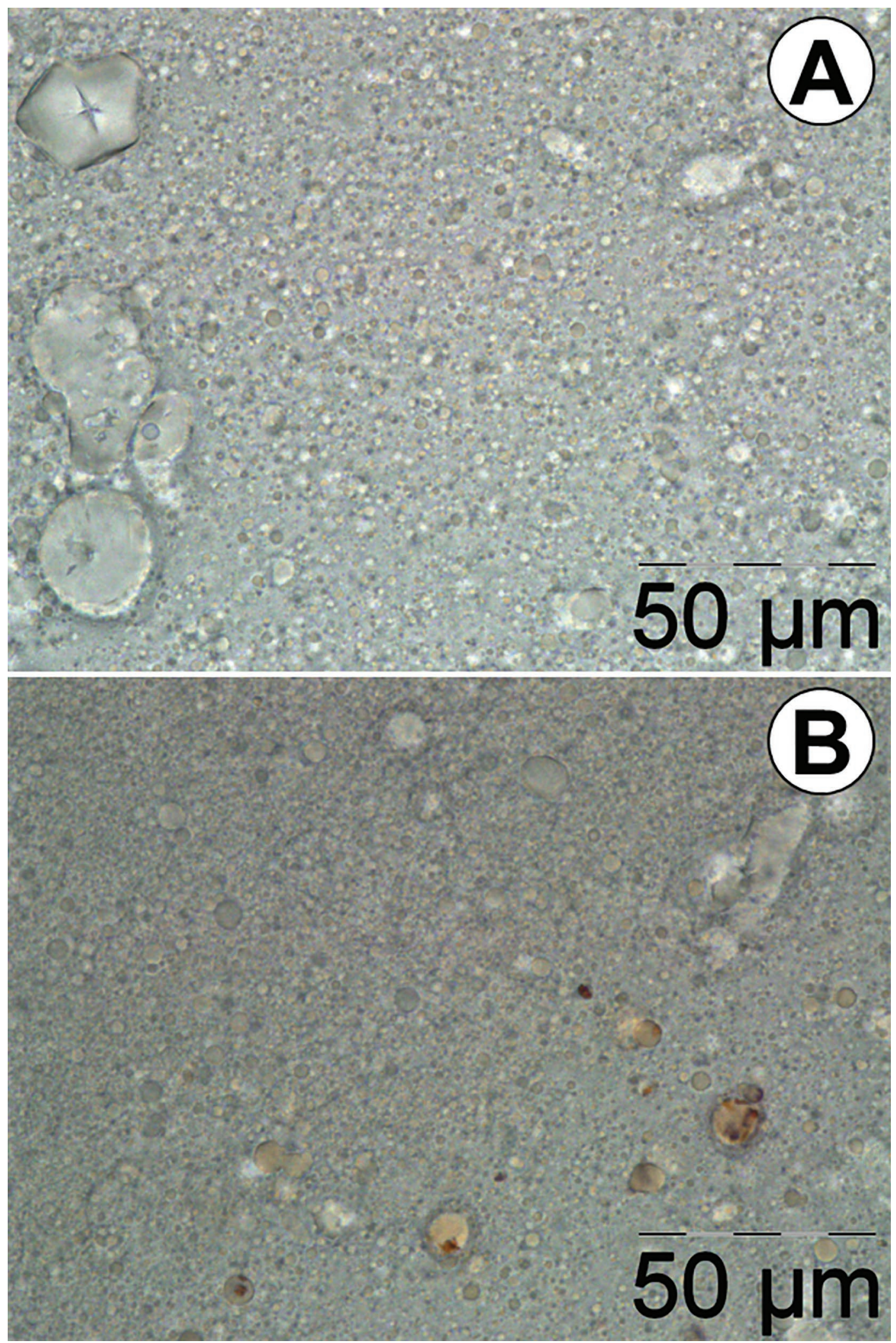

Figure 2. Photomicrographs of melted ice cream samples showing (A) control ice cream and (B) lycopene-enriched ice cream. Fat globules varying in size are present in the both samples, but stained globules apparently containing lycopene are present only in the lycopene-enriched ice cream. Some of the stained globules also contain denser material deposits that can be interpreted as the presence of crystallized lycopene. 


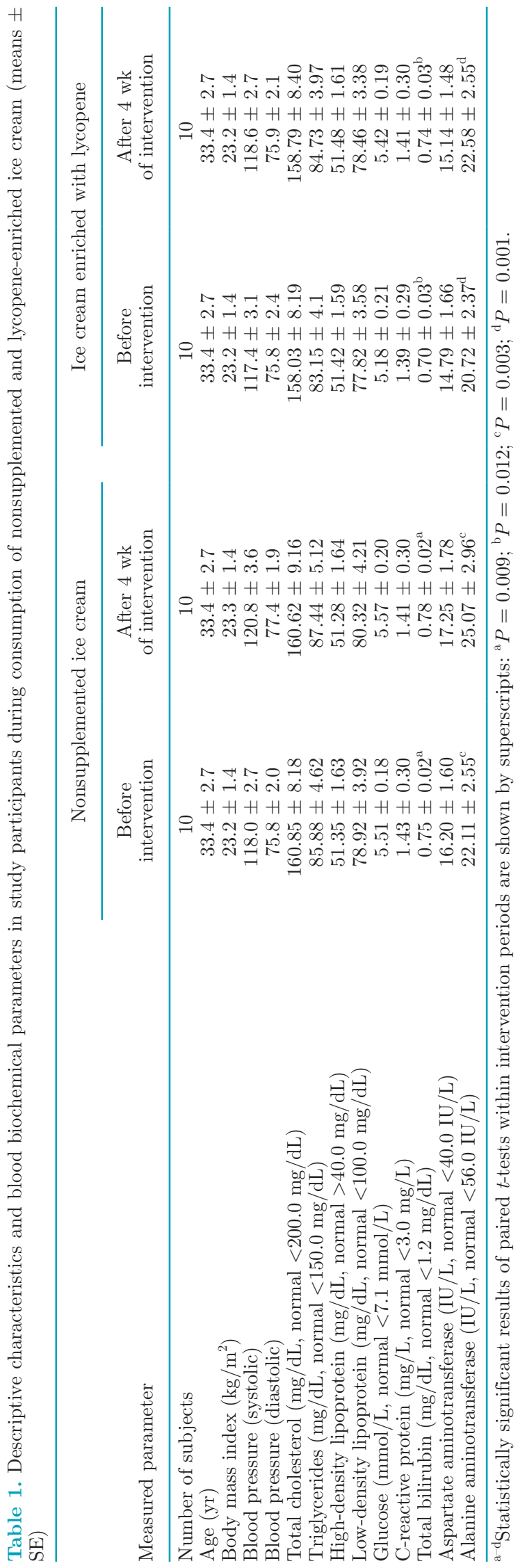

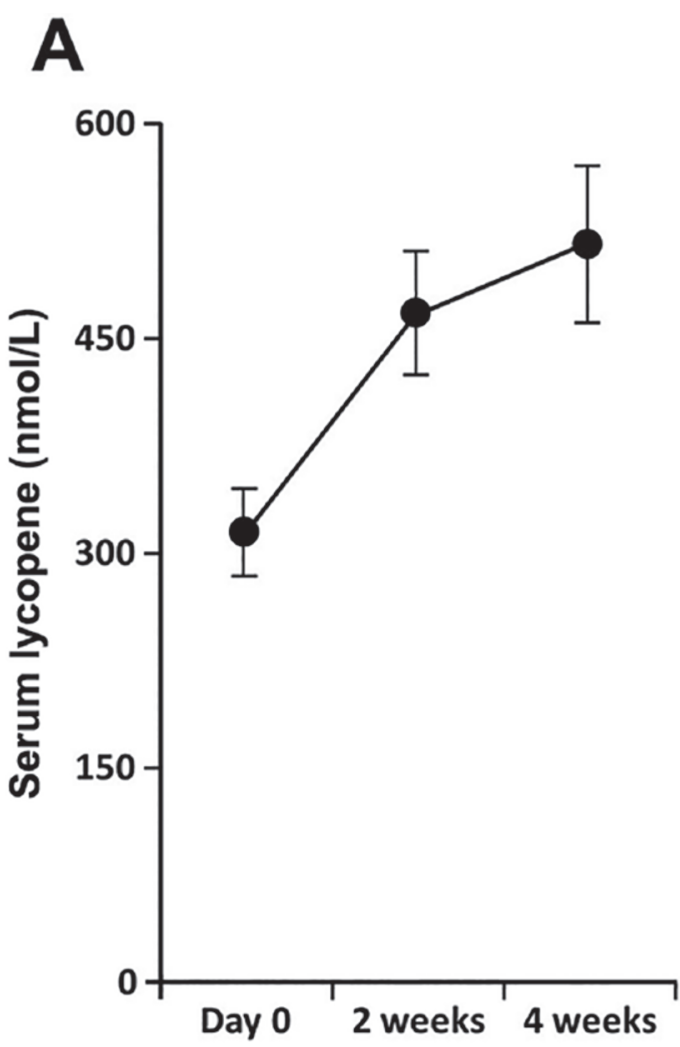
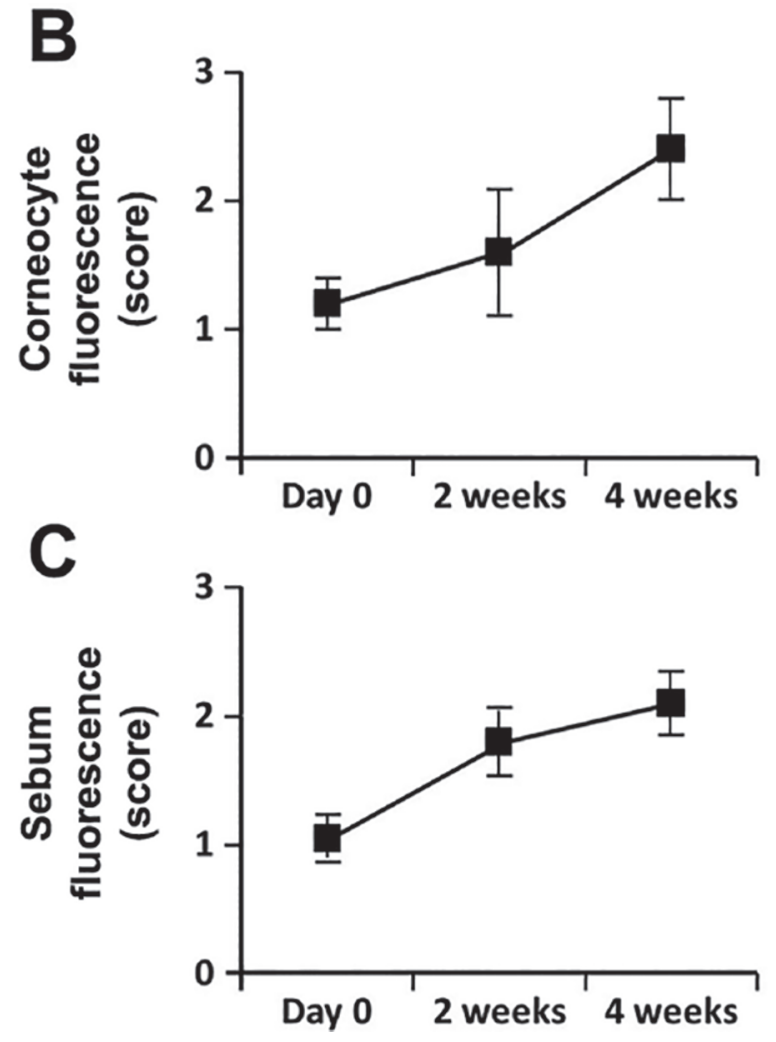

Figure 3. Lycopene concentration increases during dietary intervention with lycopene-enriched ice cream in (A) serum, (B) residual skin surface components (RSSC) desquamated corneocytes, and (C) RSSC unstructured sebum. Mean values and 95\% CI are shown. 


\section{Oxidative Damage Biomarkers in Serum Samples}

An obvious difference between dietary intervention periods was revealed for oxidative damage biomarkers. Figure 4 shows that although IOD remained practically unchanged throughout the whole period of control ice cream consumption, lycopene-enriched ice cream induced gradual IOD decline, which did not reach statistical significance after $2 \mathrm{wk}$ but became significant at the end of the dietary intervention (paired $t$-test $P=0.022$ for comparison between intervention beginning and end points). A similar pattern of changes was observed for LDL-Px (see Figure 5), with its level dropping by $46.4 \%$ at the end of the period of lycopene-enriched ice cream consumption (paired $t$-test $P=0.008$ for comparison between intervention beginning and end). In contrast, LDL-Px level remained unchanged when volunteers received control ice cream.

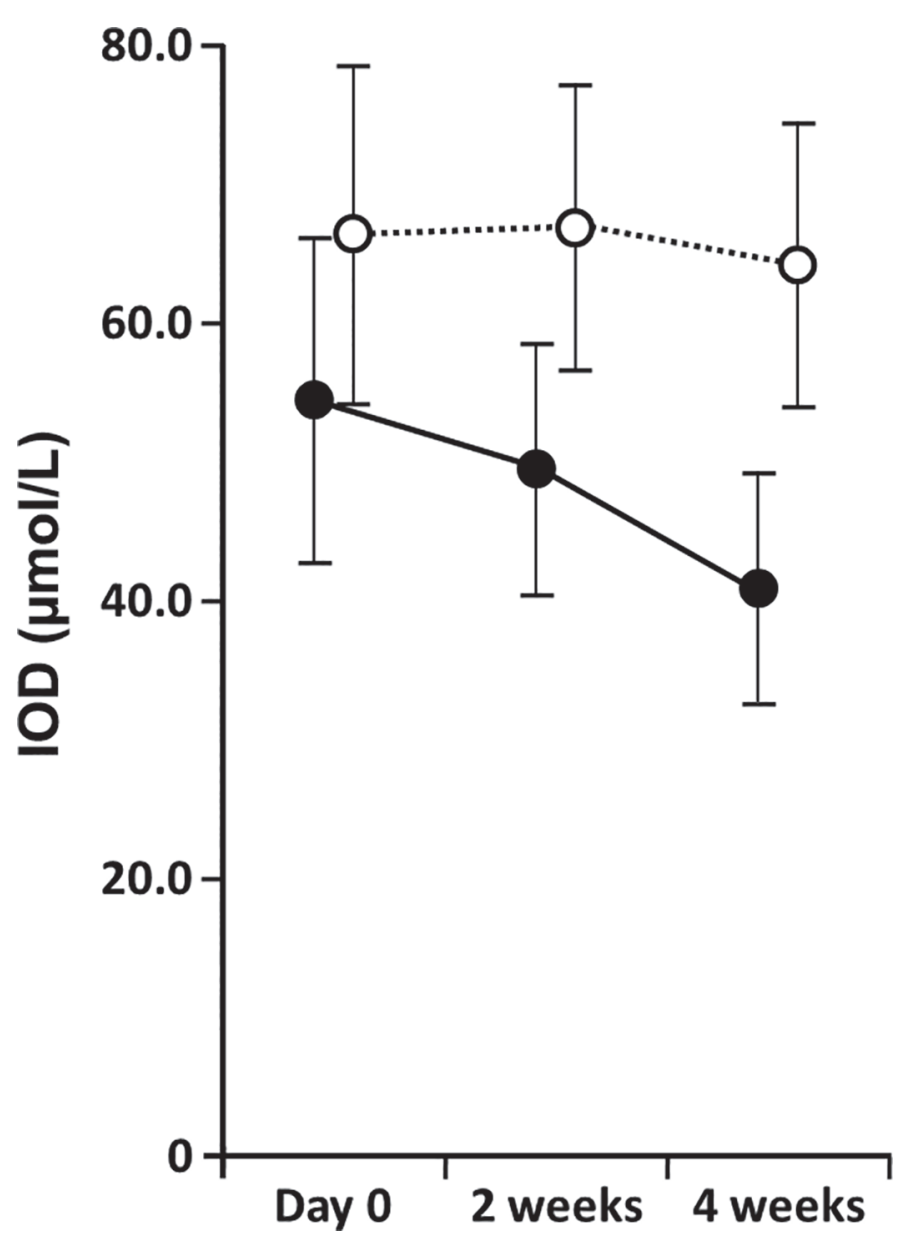

Figure 4. Inflammatory oxidative damage (IOD) dynamics during dietary interventions with control ice cream (white symbols, dotted line) and lycopene-enriched ice cream (black symbols, solid line). Mean values and $95 \%$ CI are shown.

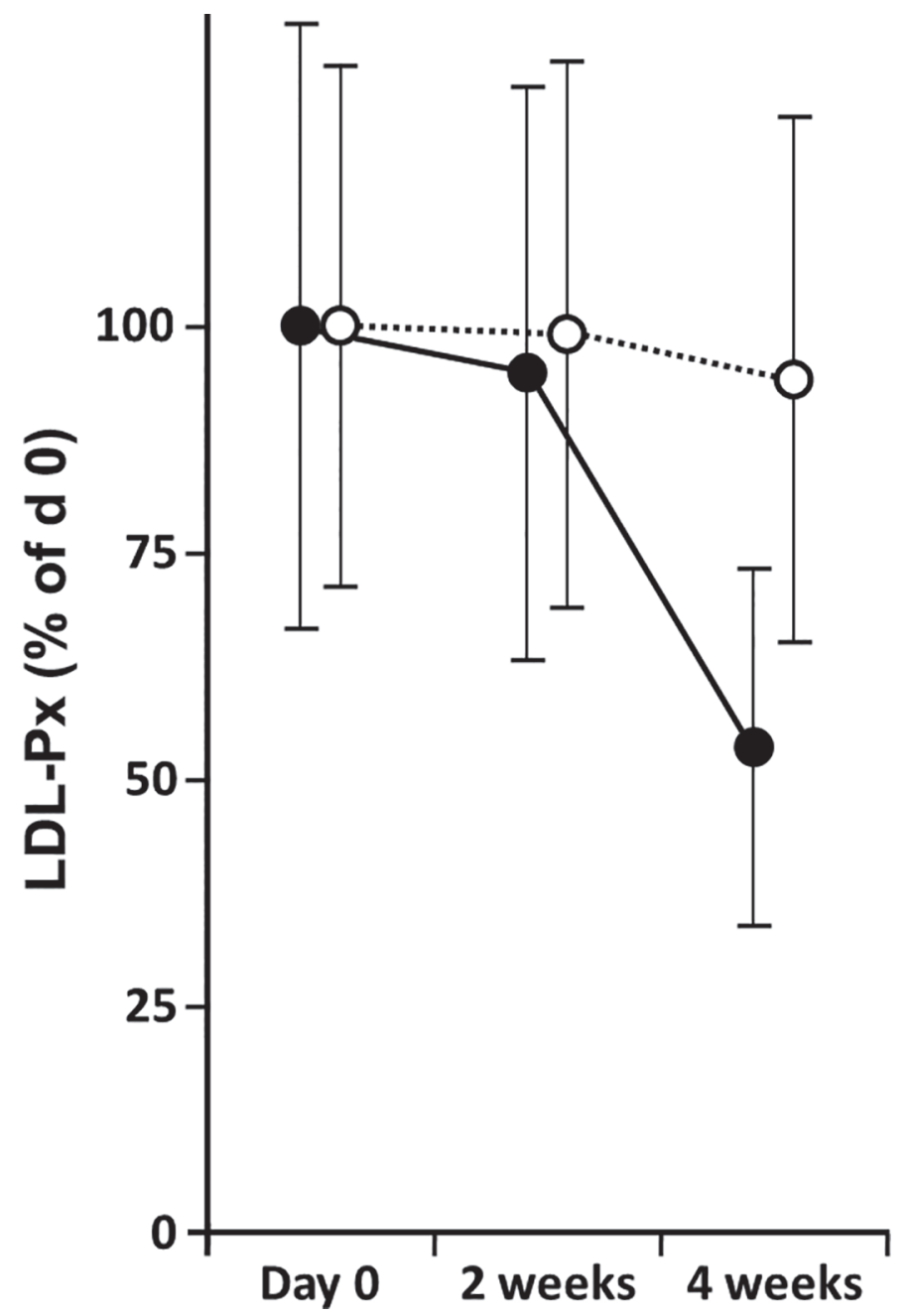

Figure 5. Serum low-density lipoprotein peroxidase protein activity (LDL-Px) dynamics during dietary interventions with control ice cream (white symbols, dotted line) and lycopene-enriched ice cream (black symbols, solid line). The LDL-Px values at the beginning of dietary intervention periods were $100 \%$, and LDL-Px levels at later points are expressed in relation to the starting point. Mean values and $95 \%$ CI are shown.

\section{Morphological Analysis of RSSC from Facial Skin Collected During Dietary Interventions}

Results of RSSC sample analysis are presented in Table 2. Measurements of lipid droplet size in the collected RSSC samples indicated that average lipid droplet size tended to decrease following 4 wk of control ice cream consumption, whereas lycopene-containing ice cream seemed to result in a slight increase of droplet size. Nevertheless, these changes failed to reach statistical significance.

Analysis of corneocyte desquamation showed that control ice cream significantly stimulated the process of corneocyte desquamation (paired $t$-test $P=0.023$ for 
comparison between intervention beginning and endig points). Lycopene enrichment weakened this effect, as only a nonsignificant desquamation increase was observed after lycopene-enriched ice cream consumption.

Likewise, the presence of gram-positive bacteria in the RSSC significantly increased by the end of the period of dietary intervention when control ice cream was consumed (paired $t$-test $P=0.028$ for comparison between intervention beginning and ending points). In contrast, bacterial presence in the RSSC slightly decreased during consumption of lycopene-enriched ice cream, but this decrease was not statistically significant (see Table 2).

\section{DISCUSSION}

Functional foods containing nutraceuticals have become an essential part of the growing range of diseasepreventing strategies, but the difficulty in incorporating nutraceutical agents into commercial food products should not be underestimated (McClements, 2015). Although lycopene is a well-known antioxidant with proven health-promoting properties and widely used as a dietary supplement (Cheng et al., 2017; Thies et al., 2017; Costa-Rodrigues et al., 2018), its lack of solubility in water, high melting point, limited chemical stability, and poor bioavailability (Reboul et al., 2006; SalviaTrujillo and McClements, 2016) present a challenge for successfully preparing new functional foods containing this carotenoid. As lycopene is fat-soluble, its bioavailability may be considerably increased if the functional food matrix is rich in fat. Indeed, an increased bioavailability of lycopene was recently demonstrated when tomato juice was ingested in combination with oil-in water excipient emulsions (Salvia-Trujillo and McClements, 2016). Ice cream is a multiphase food colloid that can be characterized as an artificially prepared frozen oil-in-water emulsion containing fat globules, air bubbles, and ice crystals that are dispersed in a freeze-concentrated solution of proteins, salts, polysaccharides, and sugars (Goff et al., 1999). Being an extremely popular milk-based dessert possessing high nutritional and caloric value, it is, however, poor in natural nutraceuticals. For this reason, attempts to improve the health-promoting properties of ice cream by supplementing it with probiotics (Cruz et al., 2009), dietary fiber (Akalin et al., 2018), and plant-derived antioxidants (Erkaya et al., 2012; Karaman et al., 2014; Sanguigni et al., 2017) have been undertaken. It should be stressed that lycopene has never been prepared in combination with ice cream before the present study. In addition, lycopene-enriched ice cream has a high content of milk fat, and it is proven that lycopene addition significantly improves milk fat stability during storage (Siwach et al., 2016). Although long-term storage effects on ice cream components were not assessed in the current study, our present work may be potentially useful for increasing stability of functional dairy-based foods enriched with lycopene.

Lycopene-containing ice cream used in our pilot study had lycopene dissolved in milk fat and incorporated in fat globules. Carotenoid dissolution during ice cream preparation could sometimes be incomplete, as occasionally lycopene crystals appeared to be present in some larger fat globules (see Figure 2B). As lycopene crystallization negatively affects its bioavailability (Shi et al., 2004), further investigation and possible optimization of lycopene preparation, such as encapsulation (Xue et al., 2013), may also be considered. Nevertheless, our early findings show that continuous consumption of lycopene-enriched ice cream clearly results in a steep increase of serum lycopene concentration during dietary intervention period (see Figure 3A).

We have previously demonstrated that lycopene supplementation improves serum lipid profiles in middle-aged patients with hypercholesterolemia (Petyaev et al., 2012, 2016), but participants of the present study were healthy young people; therefore, it was not

Table 2. Quantitative morphological characteristics of residual skin surface components collected from the surface of the facial skin before and after 4 -wk consumption of ice cream and lycopene-enriched ice cream (means $\pm \mathrm{SEM}$ )

\begin{tabular}{lccc}
\hline $\begin{array}{l}\text { Measured parameters } \\
\text { and study groups }\end{array}$ & $\begin{array}{c}\text { Before dietary } \\
\text { intervention }\end{array}$ & $\begin{array}{c}\text { After dietary } \\
\text { intervention }\end{array}$ & $\begin{array}{c}P \text {-value obtained } \\
\text { using paired } t \text {-test }\end{array}$ \\
\hline $\begin{array}{l}\text { Lipid droplet size }(\mu \mathrm{m}) \\
\quad \text { Control ice cream }\end{array}$ & $4.25 \pm 0.29$ & $4.06 \pm 0.22$ & 0.191 \\
$\quad \begin{array}{l}\text { Lycopene-enriched ice cream } \\
\text { Corneocyte desquamation (number) }\end{array}$ & $3.91 \pm 0.16$ & $4.08 \pm 0.29$ & 0.519 \\
$\quad$ Control ice cream & $113.30 \pm 17.40$ & $136.60 \pm 18.31$ & 0.023 \\
$\quad \begin{array}{l}\text { Lycopene-enriched ice cream } \\
\left.\text { Microbial presence (BPAS grade }{ }^{1}\right)\end{array}$ & $114.90 \pm 15.77$ & $126.80 \pm 20.45$ & 0.422 \\
$\quad \begin{array}{l}\text { Control ice cream } \\
\text { Lycopene-enriched ice cream }\end{array}$ & $2.03 \pm 0.11$ & $2.30 \pm 0.08$ & 0.028 \\
\hline
\end{tabular}

${ }^{1}$ Bacterial presence assessment scale (BPAS), as described in our previous paper (Chalyk et al., 2017a). 
surprising that dietary intervention with either control or lycopene-enriched ice cream did not produce any notable changes in serum lipid patterns. In contrast, significant decreases of oxidative stress biomarkers, IOD and LDL-Px, in the serum were observed when volunteers consumed lycopene-enriched ice cream. This obvious systemic effect was also manifested by lycopene accumulation in the skin, where an initial increase of lycopene concentration in the sebum was followed by a slightly delayed depositing of the carotenoid in desquamated corneocytes. This delay can be explained by the transit of terminally differentiated corneocytes through the stratum corneum that takes about $14 \mathrm{~d}$ (Haftek, 2014).

Several groups previously observed that consumption of diets rich in lycopene or dietary supplementation with this carotenoid resulted in lycopene concentrations increasing in parallel in the serum and skin (Mayne et al., 2010; Meinke et al., 2010; Scarmo et al., 2010). Dietary lycopene also protects human skin from adverse effects of UV radiation (Rizwan et al., 2011; Grether-Beck et al., 2017) and even prevents skin aging (Jenkins et al., 2014). Another aspect of human skin health that had a special interest in the context of the present study was related to observations indicating that acne development risk in young individuals increases in relation to consumption of diets rich in dairy products (Melnik, 2015; Ulvestad et al., 2017) and, in particular, ice cream (Ismail et al., 2012; Karadağ et al., 2017). Therefore, it was interesting to examine if lycopene addition to ice cream may be potentially protective against this adverse effect as well.

The stratum corneum is the most superficial layer of the epidermis, and efficient maintenance of its homeostasis through renewal and replacement of desquamated corneocytes is extremely important for skin barrier functions protecting human body from environmental influences. It is notable that corneocyte desquamation is now regarded as pyroptosis (Lachner et al., 2017), which is defined as a specific type of necrotic cell death mediated by inflammatory caspases and associated with the release of proinflammatory cytokines IL- $1 \beta$ and IL18 (Yuan et al., 2016). Moreover, it is now becoming evident that these proinflammatory changes may be stimulated in the skin by dietary factors, such as milk. Indeed, milk whey proteins were shown to activate mechanistic target of rapamycin complex 1 (mTORC1), one of the key regulators of sebum production, and milk-derived microRNA-21 and microRNA-29a appear to contribute to IL-1 $\beta$ secretion upregulation in the skin (Melnik, 2015). These molecular events are likely to be responsible for keratinocyte hyperproliferation, leading to enhanced formation of corneocytes and increased desquamation. In addition, elevated sebum production promotes Propionibacterium acnes overgrowth on the surface of the facial skin (Zouboulis et al., 2014) and may eventually lead to the development of acne.

Our analysis of samples collected before and after dietary interventions has demonstrated that control ice cream consumption for 4 wk results in statistically significant increases $(P<0.05)$ of both corneocyte desquamation from the $\mathrm{SC}$ and the presence of grampositive microorganisms in the RSSC (see Table 2). Although continuous ice cream consumption did not result in acne development (this was not expected, as most of our volunteers were close to 30 yr old), morphological alterations of the RSSC associated with control ice cream intake were likely to reflect manifestations of oxidative stress and mild proinflammatory changes.

In contrast, neither corneocyte desquamation level nor bacterial presence in the RSSC increased during dietary intervention with lycopene-enriched ice cream. Interestingly, convincing experimental evidence exists demonstrating that lycopene inhibits proinflammatory cytokines, including IL-1 $\beta$ (Palozza et al., 2011; Zhao et al., 2017); thus, our results can be interpreted as a manifestation of antioxidant and anti-inflammatory lycopene action at the level of the facial skin. The observed prevention of bacterial overgrowth by lycopene may be caused by sebum production normalization; however, direct antibacterial action of the carotenoid is impossible to exclude, as it was certainly present in the sebum of our volunteers during consumption of lycopene-enriched ice cream. Lycopene's bactericidal effect against Escherichia coli was previously described (Lee and Lee, 2014), but this remains poorly investigated.

Our study had limitations. Lycopene-enriched ice cream is a new product that needs further characterization (e.g., investigation of long-term storage effects on ice cream characteristics and lycopene stability) and possible modifications in manufacturing technology (e.g., lycopene encapsulation). Further work should address these points. Moreover, we assessed only 10 volunteers; thus, our findings need to be confirmed in a larger study. Precise lycopene dosing may be difficult to determine, as crystallized lycopene still detectable in the lycopene-enriched ice cream could affect carotenoid bioavailability. In addition, the RSSC analysis applied in our study used only morphological and immunofluorescent approaches, so it was not possible to fully characterize bacteria present in this material or precisely quantify lycopene concentration changes. Nevertheless, we were able to observe a few interesting phenomena associated with the difference between dietary interventions based on consuming either control or lycopene-enriched ice cream. 


\section{CONCLUSIONS}

Taken together, our results allow several conclusions. (1) Ice cream enrichment with lycopene did not alter sensory characteristics of the product, (2) consumption of lycopene-enriched ice cream resulted in a steep increase of lycopene concentration in the serum and skin of volunteers undergoing the dietary intervention, and (3) significant decreases of systemic oxidative stress biomarkers (IOD and LDL-px) were observed during consumption of lycopene-enriched ice cream, whereas control ice cream did not provoke any changes. (4) Continuous consumption of control ice cream affected facial skin by increasing both corneocyte desquamation and gram-positive microbiota presence in the RSSC collected from the surface of the skin. Finally, (5) continuous consumption of lycopene-enriched ice cream was not associated with any changes of facial RSSC composition. It appears that lycopene incorporated in the ice cream exerts beneficial antioxidant effects both systemically and at the level of the facial skin. The latter action may be especially useful in terms of preventing the potential acne-promoting influence of ice cream consumption in young individuals.

\section{ACKNOWLEDGMENTS}

Volunteers who took part in the study are thanked for their cooperation. Alexandre Loktionov (DiagNodus Ltd., Cambridge, UK) is thanked for his critical advice and help in manuscript preparation. This research did not receive any specific grant from funding agencies in the public, commercial, or not-for-profit sectors. The authors of this publication have no conflict of interest to report.

\section{REFERENCES}

Akalin, A. S., H. Kesenkas, N. Dinkci, G. Unal, E. Ozer, and O. Kinik. 2018. Enrichment of probiotic ice cream with different dietary fibers: Structural characteristics and culture viability. J. Dairy Sci. 101:37-46.

Al-Shobaili, H. A., A. A. Alzolibani, A. A. Al Robaee, A.-R. M. A. Meki, and Z. Rasheed. 2013. Biochemical markers of oxidative and nitrosative stress in acne vulgaris: Correlation with disease activity. J. Clin. Lab. Anal. 27:45-52.

Blume-Peytavi, U., A. Rolland, M. E. Darvin, A. Constable, I. Pineau, C. Voit, K. Zappel, G. Schäfer-Hesterberg, M. Meinke, R. L. Clavez, W. Sterry, and J. Lademann. 2009. Cutaneous lycopene and $\beta$-carotene levels measured by resonance Raman spectroscopy: High reliability and sensitivity to oral lactolycopene deprivation and supplementation. Eur. J. Pharm. Biopharm. 73:187-194.

Burton-Freeman, B., and H. D. Sesso. 2014. Whole food versus supplement: Comparing the clinical evidence of tomato intake and lycopene supplementation on cardiovascular risk factors. Adv. Nutr. $5: 457-485$.

Chalyk, N. E., T. Y. Bandaletova, N. H. Kyle, and I. M. Petyaev. 2017a. Age-related differences in morphological characteristics of residual skin surface components collected from the surface of facial skin of healthy male volunteers. Skin Res. Technol. 23:212-220.

Chalyk, N. E., V. A. Klochkov, T. Y. Bandaletova, N. H. Kyle, and I. M. Petyaev. 2017b. Continuous astaxanthin intake reduces oxidative stress and reverses age-related morphological changes of residual skin surface coimponents in middle-aged volunteers. Nutr. Res. 48:40-48.

Cheng, H. M., G. Koutsidis, J. K. Lodge, A. Ashor, M. Siervo, and J. Lara. 2017. Tomato and lycopene supplementation and cardiovascular risk factors: A systemic review and meta-analysis. Atherosclerosis 257:100-108.

Costa-Rodrigues, J., O. Pinho, and P. R. R. Monteiro. 2018. Can lycopene be considered an effective protection against cardiovascular disease? Food Chem. 245:1148-1153.

Cruz, A. G., A. E. C. Antunes, A. L. O. P. Sousa, J. A. F. Faria, and S. M. I. Saad. 2009. Ice-cream as a probiotic food carrier. Food Res. Int. 42:1233-1239.

Davies, J. M. S., J. Cillard, B. Friguet, E. Cadenas, J. Cadet, R. Cayce, A. Fishmann, D. Liao, A.-L. Bulteau, F. Derbré, A. Rébillard, S. Burstein, E. Hirsch, R. A. Kloner, M. Jakowec, G. Petzinger, D. Sauce, F. Senlaub, I. Limon, F. Ursini, M. Maiorini, C. Economides, C. J. Pike, P. Cohen, A. N. Salvayre, M. R. Halliday, A. J. Lindquist, N. A. Jakowec, F. Mehta-Grigoriou, M. Mericskay, J. Mariani, Z. Li, D. Huang, E. Grant, H. J. Forman, C. E. Finch, P. Y. Sun, L. C. D. Pomatto, O. Aqbulut, D. Warburton, C. Neri, M. Rouis, P. Cillard, J. Capeau, J. Rozenbaum, and K. J. A. Davies. 2017. The oxygen paradox, the French paradox, and age-related diseases. Geroscience 39:499-550.

Diwadkar-Navsariwala, V., J. Novotny, D. Custin, J. A. Sosman, K. A. Rodvold, J. A. Crowell, M. Stacewicz-Sapuntzakis, and P. E. Bowen. 2003. A physiological pharmacokinetic model describing the disposition of lycopene in healthy men. J. Lipid Res. 44:1927-1939.

Erkaya, T., E. Dağdemir, and M. Şengül. 2012. Influence of Cape gooseberry (Physalis peruviana L.) addition on the chemical and sensory characteristics and mineral concentrations of ice cream. Food Res. Int. 45:331-335.

Goff, H. D., E. Verespej, and A. K. Smith. 1999. A study of fat and air structures in ice cream. Int. Dairy J. 9:817-829.

Grether-Beck, S., A. Marini, T. Jaenicke, W. Stahl, and J. Krutmann. 2017. Molecular evidence that oral supplementation with lycopene or lutein protects human skin against ultraviolet radiation: Results from a double-blinded, placebo-controlled crossover study. Br. J. Dermatol. 176:1231-1240.

Haftek, M. 2014. 'Memory' of the stratum corneum: Exploration of the epidermis' past. Br. J. Dermatol. 171(Suppl.3):6-9.

Hunter, P. M., and R. A. Hegele. 2017. Functional foods and dietary supplements for the management of dyslipidemia. Nat. Rev. Endocrinol. 13:278-288.

Ismail, N. H., Z. A. Manaf, and N. F. Azizan. 2012. High glycemic load diet, milk and ice cream consumption are related to acne vulgaris in Malaysian young adults: A case control study. BMC Dermatol. 12:13. https://doi.org/10.1186/1471-5945-12-13.

Jenkins, G., L. J. Wainwright, R. Holland, K. E. Barrett, and J. Casey. 2014. Wrinkle reduction in post-menopausal women consuming a novel oral supplement: A double-blind placebo-controlled randomized study. Int. J. Cosmet. Sci. 36:22-31.

Kammeyer, A., and R. M. Luiten. 2015. Oxidation events and skin aging. Ageing Res. Rev. 21:16-29.

Karadağ, A. S., İ. Balta, H. Saricaoğlu, S. Kiliç, K. H. Kelekçi, M. Yildirim, D. A. Arica, S. Öztürk, G. Karaman, A. A. Çerman, S. G. Bilgili, E. Turan, M. M. Demirci, T. K. Uzunçakmak, S. C. Güvenç, A. Ataseven, A. Ferahbaş, B. Aksoy, E. Çölgeçen, Ö. Ekiz, F. Topaloğly Demir, Ö. Bilgiç, S. Cakmak, D. Uçmak, P. Özuğuz, Y. Kaymak Konkuralp, A. T. Ermertcan, G. Gökdemir, E. Bülbül Başkan, G. Alyamaç, and H. Sanli. 2017. The effect of personal, familial, and environmental characteristics on acne vulgaris: A prospective, multicentre, case controlled study from Turkey. G. Ital. Dermatol. Venereol. https://doi.org/10.23736/S0392-0488.17 $.05532-8$.

Karaman, S., Ö. S. Toker, F. Yüksel, M. Çam, A. Kayacier, and M Dogan. 2014. Physicochemical, bioactive, and sensory properties 
of persimmon-based ice cream: Technique for order preference by similarity to ideal solution to determine optimum concentration. J. Dairy Sci. 97:97-110.

Kaulmann, A., and T. Bohn. 2014. Carotenoids, inflammation, and oxidative stress-Implications of cellular signalling pathways and relation to chronic disease prevention. Nutr. Res. 34:907-929.

Lachner, J., V. Mlitz, E. Tschachler, and L. Eckhart. 2017. Epidermal cornification is preceded by the expression of a keratinocyte-specific set of pyroptosis-related genes. Sci. Rep. 7:17446. https://doi .org/10.1038/s41598-017-17782-4.

Lee, W., and D. H. Lee. 2014. Lycopene-induced hydroxyl radical causes oxidative DNA damage in Escherichia coli. J. Microbiol. Biotechnol. 24:1232-1237.

Mayne, S. T., B. Cartmel, S. Scarmo, H. Lin, D. Leffell, E. Welch, P. Bhosale, P. S. Bernstein, and W. Gellermann. 2010. Noninvasive assessment of dermal carotenoids as a biomarker of fruit and vegetable intake. Am. J. Clin. Nutr. 92:794-800.

McClements, D. J. 2015. Enhancing nutraceutical bioavailability through food matrix design. Curr. Opin. Food Sci. 4:1-6.

Meinke, M. C., M. E. Darvin, H. Vollert, and J. Lademann. 2010. Bioavailability of natural carotenoids in human skin compared to blood. Eur. J. Pharm. Biopharm. 76:269-274.

Melnik, B. C. 2015. Linking diet to acne metabolomics, inflammation, and comedogenesis: An update. Clin. Cosmet. Investig. Dermatol. $8: 371-388$.

Moran, N. E., J. V. Erdman Jr., and S. K. Clinton. 2013. Complex interactions between dietary and genetic factors impact lycopene metabolism and distribution. Arch. Biochem. Biophys. 539:171180.

Palozza, P., R. Simone, A. Catalano, G. Monego, A. Barini, M. C. Mele, N. Parrone, S. Trombino, N. Picci, and F. O. Ranelletti. 2011. Lycopene prevention of oxysterol-induced proinflammatory cytokine cascade in human macrophages: inhibition of NF-kB nuclear binding and increase in PPAR $\gamma$ expression. J. Nutr. Biochem. 22:259-268.

Petyaev, I., M. M. Mitchinson, J. V. Hunt, and P. J. Coussons. 1998. Superoxide dismutase activity of antibodies purified from the human arteries and atherosclerotic lesions. Biochem. Soc. Trans. 26:S43.

Petyaev, I. M. 2016. Lycopene deficiency in ageing and cardiovascular disease. Oxid. Med. Cell. Longev. 2016:3218605. https://doi.org/ $10.1155 / 2016 / 3218605$

Petyaev, I. M., and P. J. Coussons. 1999. Superoxide dismutase activity of antibodies purified from human atherosclerotic lesions. Pages 51-44 in Superoxide Dismutases: Recent Advances and Clinical Applications. M. A. Edeas, ed. Editions Mel, Paris, France.

Petyaev, I. M., P. Y. Dovgalevsky, N. E. Chalyk, V. A. Klochkov, and N. Kyle. 2014. Reduction in blood pressure and serum lipids by lycosome formulation of dark chocolate and lycopene in prehypertension. Food Sci. Nutr. 2:744-750.

Petyaev, I. M., P. Y. Dovgalevsky, N. E. Chalyk, V. A. Klochkov, and N. Kyle. 2016. Reduction of cholesterol and markers of oxidation in serum of hypercholesterolemic patients treated with lycosome formulation of simvastatin. Int. J. Res. Med. Sci. 4:349-355.

Petyaev, I. M., P. Y. Dovgalevsky, V. A. Klochkov, N. E. Chalyk, and N. Kyle. 2012. Whey protein lycosome formulation improves vascular functions and plasma lipids with reduction of markers of inflammation and oxidative stress in prehypertension. ScientificWorldJournal 2012:269476. https://doi.org/10.1100/2012/269476.

Rao, A. V., and L. G. Rao. 2007. Carotenoids and human health. Pharmacol. Res. 55:207-216.

Reboul, E., M. Richelle, E. Perrot, C. Desmoulins-Malezet, V. Pirisi, and P. Borel. 2006. Bioaccessibility of carotenoids and vitamin E from their main dietary sources. J. Agric. Food Chem. 54:87498755 .
Rizwan, M., I. Rodriguez-Blanco, A. Harbottle, M. A. Birch-Machin, R. E. B. Watson, and L. E. Rhodes. 2011. Tomato paste rich in lycopene protects against cutaneous photodamage in humans in vivo: a randomized controlled trial. Br. J. Dermatol. 164:154-162.

Rodgers, S. 2016. Minimally processed functional foods: technological and operational pathways. J. Food Sci. 81:R2309-R2319.

Ross, A. B., L. T. Vuong, J. Ruckle, H. A. Synal, T. Shulze-König, K. Wertz, R. Rümbeli, R. G. Liberman, P. L. Skipper, S. R. Tannenbaum, A. Bourgeois, P. A. Guy, M. Enslen, I. L. Nielsen, S. Kochhar, M. Richelle, L. B. Fay, and G. Williamson. 2011. Lycopene bioavailability and metabolism in humans: an accelerator mass spectrometry study. Am. J. Clin. Nutr. 93:1263-1273.

Sahib, A. S., H. H. Al-Anbari, and A. R. Abu Raghif. 2013. Oxidative stress in acne vulgaris: An important therapeutic target. J. Mol. Pathophysiol. 2:27-31. https://doi.org/10.5455/jmp .20130127102901.

Salvia-Trujillo, L., and D. J. McClements. 2016. Enhancement of lycopene bioaccessibility from tomato juice using excipient emulsions: Influence of lipid droplet size. Food Chem. 210:295-304.

Sanguigni, V., M. Manco, R. Sorge, L. Gnessi, and D. Francomano. 2017. Natural antioxidant ice cream acutely reduces oxidative stress and improves vascular function and physical performance in healthy individuals. Nutrition 33:225-233.

Scarmo, S., B. Cartmel, H. Lin, D. J. Leffell, E. Welch, P. Bhosale, P. S. Bernstein, and S. T. Mayne. 2010. Significant correlations of dermal total carotenoids and dermal lycopene with their respective plasma levels in healthy adults. Arch. Biochem. Biophys. 504:34-39.

Shi, J., Q. Qu, Y. Kakuda, D. Yeung, and Y. Jiang. 2004. Stability and synergistic effect of antioxidative properties of lycopene and other active components. Crit. Rev. Food Sci. Nutr. 44:559-573.

Siwach, R., J. Tokas, and R. Seth. 2016. Use of lycopene as a natural antioxidant in extending the shelf-life of anhydrous cow milk fat. Food Chem. 199:541-546.

Tang, Z., C. Wu, and L. Shi. 2015. Use of encapsulation technology for improving the stability of lycopene. Pages $115-128$ in Lycopene: Food Sources, Potential Role in Human Health and Antioxidant Effects. J. R. Bailey, ed. Nova Science Publishers, New York, NY.

Thies, F., L. M. Mills, S. Moir, and L. F. Masson. 2017. Cardiovascular benefits of lycopene: Fantasy or reality? Proc. Nutr. Soc. $76: 122-129$.

Tsibezov, V. V., Y. K. Bashmakov, D. V. Pristenskiy, N. A. Zigangirova, L. V. Kostina, N. E. Chalyk, A. Y. Kozlov, E. Y. Morgunova, M. P. Chernyshova, M. V. Lozbyakova, N. H. Kyle, and I. M. Petyaev. 2017. Generation and application of monoclonal antibody against lycopene. Monoclon. Antib. Immunodiagn. Immunother. 36:62-67.

Ulvestad, M., E. Bjertness, F. Dalgard, and J. A. Halvorsen. 2017. Acne and dairy products in adolescence: Results from a Norwegian longitudinal study. J. Eur. Acad. Dermatol. Venereol. 31:530-535.

Xue, F., C. Li, Y. Liu, X. Zhu, S. Pan, and L. Wang. 2013. Encapsulation of tomato oleoresin with zein prepared from corn gluten meal. J. Food Eng. 119:439-445.

Yuan, J., A. Najafov, and B. F. Py. 2016. Roles of caspases in necrotic cell death. Cell 167:1693-1704.

Zhao, B, B. Ren, R. Guo, W. Zhang, S. Ma, Y. Yao, T. Yuan, Z. Liu, and X. Liu. 2017. Supplementation of lycopene attenuates oxidative stress induced neuroinflammation and cognitive impairment via Nrf2/NF-kB transcriptional pathway. Food Chem. Toxicol. 109:505-516.

Zouboulis, C. C., E. Jourdan, and M. Picardo. 2014. Acne is an inflammatory disease and alterations of sebum composition initiate acne lesions. J. Eur. Acad. Dermatol. Venereol. 28:527-532. 